\title{
A Novel Heart-Centered, Gratitude-Meditation Intervention to Increase Well-Being among Adolescents
}

\author{
Lunthita M. Duthely, ${ }^{1,2}$ Sandra G. Nunn, ${ }^{2}$ and John T. Avella ${ }^{2}$ \\ ${ }^{1}$ University of Miami, Miller School of Medicine, P.O. Box 016960 (D-53), Miami, FL 33101, USA \\ ${ }^{2}$ Center for Educational and Instructional Technology Research (CEITR), University of Phoenix, 1625 W. Fountainhead Pkwy, \\ Tempe, AZ 85282, USA
}

Correspondence should be addressed to Lunthita M. Duthely; lduthely@med.miami.edu

Received 13 May 2017; Accepted 7 August 2017; Published 16 October 2017

Academic Editor: Gwo-Jen Hwang

\begin{abstract}
Copyright (C) 2017 Lunthita M. Duthely et al. This is an open access article distributed under the Creative Commons Attribution License, which permits unrestricted use, distribution, and reproduction in any medium, provided the original work is properly cited.

Population studies paint a dismal picture of the mental health status of adolescents, in the US and worldwide. Positive psychology, which takes a preventative approach to keeping individuals in higher states of well-being, is being implemented increasingly among youth, with the goal of avoiding future mental health and psychological problems. In this study, a novel intervention, which fused the practice of meditation with gratitude visualizations, was tested among adolescents. The purpose of this quasi-experimental study was to determine the extent to which the intervention affected life satisfaction, school satisfaction, and measured gratitude, among a culturally diverse cohort of adolescents. Instrumentation consisted of three positive psychology measures-the Student Life Satisfaction Scale, the School Satisfaction Subscale, and the Gratitude Questionnaire-Six-Item Form. Participants were randomly assigned either to the delayed-intervention, no-treatment control group or to the experimental group. The four-week intervention was manualized primarily from the heart-centered gratitude visualizations outlined in a happiness and positive emotions handbook, The Jewels of Happiness: Inspiration and Wisdom to Guide Your Life-Journey. The intervention significantly affected life satisfaction, school satisfaction, and gratitude of the experimental group, when compared to the control group. Medium to large effect sizes were detected using the ANCOVA statistical test.
\end{abstract}

\section{Introduction}

Population studies paint a dismal picture of the mental health status of adolescents. The World Health Organization (WHO) estimates that $10-20 \%$ of adolescents live with some type of mental health disorder [1]. Depression is the number one cause of mental illness, whereas suicide is the third leading cause of death among adolescents worldwide [2]. In the United States (US), one-third of adolescents report feeling sad or hopeless [3]. Among high school students, about one in six (17\%) seriously considered attempting suicide [2]. The Centers for Disease Control (CDC) reported that selfinflicted injury (suicide) has persisted as the third leading cause of death among adolescents in the US [4].

The adolescent period is the crucial time along the spectrum of transitioning between childhood and adulthood, but, for some youth living in the US, this period is challenged by mental illness and psychological symptoms $[5,6]$. Schools are in a unique position to affect positive outcomes for youth because of the relatively large amount of time youth spend in school [7]. Specifically, the time children and adolescents spend at school is ideal for conducting well-being interventional studies [8].

The well-being paradigm is a preventative approach of addressing adolescents' mental health and wellness. Different constructs measure youth well-being, including happiness, subjective well-being, and life satisfaction [9]. Longitudinally, higher well-being in adolescence correlated to fewer, risky health behaviors later in young adulthood [10]. Higher wellbeing was predictive also of fewer psychological symptoms [11], increased academic achievement [12, 13], and better student engagement [14]. Despite the growing number of life 
satisfaction studies, more studies are needed (see [14-17]) to enable educators, school psychologists, and other mental health professionals to measure adolescent life satisfaction.

The construct of school engagement, measured as school satisfaction, is related to school dropout and represents students' emotional engagement with their school experiences [14]. Early and middle adolescence occurs just before the end of the compulsory education period and is a critical time to test interventions that could prevent school dropout [14]. Taken together, this study addressed the paucity of interventional studies, particularly among culturally diverse populations [18], that examined life satisfaction [14-17] and school satisfaction among adolescents [14].

One approach to increasing well-being among youth is the positive psychology (PS) approach outlined in Seligman [19]. Comprehensive metareviews [20, 21] documented the effectiveness of youth PS interventions. Nearly a decade after Seligman and Csikszentmihalyi [22] introduced the PS paradigm, Seligman et al. [23] summarized the progress made in youth-focused research and programs. Support for PS school-based programs and curricula, called positive education, continues to grow [24]. The PS approach, studied among both youth and adults [25], proved effective in increasing youth well-being, using a variety of methods, such as schoolbased interventions to increase the emotion of gratitude [26]. Meta-analyses demonstrated that gratitude interventions among adolescents were the most effective of all PS interventions [27].

Another approach to increasing youth well-being is the secular practice of meditation. Meditation tested in clinical and educational settings positively affected youth behavioral, mental health, and academic outcomes [28]. Researchers noted that meditation was seldom included within the preventative, well-being paradigm (e.g., [29]). Researchers noted also that more meditation interventional studies are needed within the well-being paradigm (e.g., [30-32]). Also, greater attention has been called to the practice of meditation as a way to improve the lives of school-aged children and adolescents and the overall quality of education in the US [33].

Several forms of meditation are documented in the literature. The meditation technique used in this study is the heart-centered meditation techniques and visualizations outlined in the positive emotions handbook, The Jewels of Happiness: Inspiration and Wisdom to Guide Your Life-Journey [34]. The author [34] posits that cultivating different positive qualities, particularly the qualities of peace and gratitude, increases life satisfaction and happiness of the practitioner. The meditation techniques were combined with visualization exercises to invoke the quality of gratitude, as described in the handbook. The primary author of the current study, who was trained in the use of the aforementioned techniques, conducted the 4-week intervention and administered the assessments.

The aim of this study was to test a novel gratitudemeditation intervention among a cohort of ethnically diverse adolescents. A paucity of well-being interventions conducted among adolescents, particularly culturally diverse adolescents, was noted in the literature. A delayed-intervention control group served as the comparison group for this quasiexperimental study. A quasi-experimental study design, common in educational research, was chosen for several reasons: (1) the study was conducted among intact classrooms of middle schools students; (2) true randomization was not possible; and (3) because the study was conducted in a natural classroom environment, certain conditions could not be controlled for.

To that end, in order to assess the effect the gratitudemeditation intervention (the independent variable) has on life satisfaction, school satisfaction, and gratitude (dependent variables), among this cohort of culturally diverse adolescents, attending a US middle school, the following research questions guided the study and statistical analyses:

R1: to what extent does the gratitude-meditation intervention affect measured life satisfaction in the treatment group compared to the control group?

Null hypothesis (H1o): life satisfaction, following the gratitude-meditation intervention, is not significantly different between the treatment group and the control group.

R2: to what extent does the gratitude-meditation intervention affect measured school satisfaction in the treatment group compared to the control group?

Null hypothesis (H2o): school satisfaction, following the gratitude-meditation intervention, is not significantly different between the treatment group and the control group.

R2: to what extent does the gratitude-meditation intervention affect measured gratitude in the treatment group compared to the control group?

Null hypothesis (H2o): measured gratitude, following the gratitude-meditation intervention, is not significantly different between the treatment group and the control group.

1.1. Gratitude and Well-Being: Correlational Studies. The gratitude construct has been correlated with well-being among children as young as age seven [35]. Research conducted among youth emanated from findings of the relatedness of measured gratitude to the physical, emotional, and social health of adults [27]. Positive correlations between gratitude and general well-being, psychological well-being, school experiences [27], and academically related outcomes among children and adolescents have been documented [36, 37].

Longitudinal studies provided stronger evidence of the positive relationship between gratitude and well-being. As an example, Froh et al.s [38] study correlated increased gratitude with significant increases in social integration among 700 middle school students followed for up to six months. Prosocial behavior, defined as using one's strengths and abilities to help others, and life satisfaction mediated the relationship between gratitude and social integration. In the aforementioned study, social integration and 
gratitude serially influenced each other-students whose level of gratitude increased significantly over six months also significantly increased their levels of social integration [38].

1.2. Gratitude Interventions. An initial study examining the relationship between gratitude and adolescent well-being demonstrated that a grateful outlook (counting blessings) significantly increased gratitude, life satisfaction, and optimism and decreased negative affect (emotions) among 221 middle school students in the 6 th and 7 th grade [39]. In their three-armed intervention, Froh et al. [39] noted that the most significant finding was the strong relationship between counting blessings and satisfaction with school experience. This relationship was significant compared to both the counting "hassles" (or burdens) group and the control group [39, p. 213]. The aforementioned authors, who used the Gratitude Adjective Checklist (GAC), reported a small effect size for increasing gratitude in the counting blessings group at eight days (GAC; $F[2,213]=3.92, p<0.05, \eta^{2}=$ $0.04)$ and at a 3-week follow-up data point $(F[2,208]=$ 4.48, $\left.p=0.01, \eta^{2}=0.04\right)$. No significant difference emerged for the positive affect of well-being; a significant small effect size was detected for decreased negative affect [39].

Making gratitude visits was the second type of intentional activity tested among adolescents. Several studies demonstrated positive outcomes among adolescents. Froh et al's [27] study included 89 children and adolescents, grades 3, 8 , and 12 , enrolled in a parochial school. Making gratitude visits, compared to expressing feelings from the previous day, enhanced subjective well-being. Subjective well-being, measured by a combination of positive and negative affects (emotions), was moderated by (lower) positive affects. The findings confirmed the researchers' hypothesis: youth with lower positive affect achieved higher levels of gratitude. Froh et al. [27] reported no significant effect on increasing gratitude. The third type of gratitude intervention is a benefits appraisal study. In the first of its kind, Froh et al. [37] demonstrated the long-term effects (up to five months) of a gratitude curriculum designed to teach 112 children and adolescents, eight to 11 years old, to recognize, acknowledge, and appraise help that was received from another person. The aforementioned authors [37] reported a small effect size $\left(\mathrm{GAC} ; F[1,95]=4.25, p<0.05, \eta^{2}=0.04\right)$.

Froh and Bono [40], leading researchers in the area of child and adolescent gratitude interventions, outlined different gratitude-increasing activities educators can implement to enhance student social skills and academic success. The authors suggested reflecting on the benefits of gratitude, reflecting on the different ways to practice gratitude, dedicating a time of the year to express gratitude, and writing gratitude cards to others from whom they received help. Although the first gratitude interventional studies among youth emerged in 2008, Froh and Bono [40] concluded that the evidence suggests that fostering gratitude encourages "healthy development" (p. 28). Further, gratitude brings not only benefit to the individual but also a social benefit, a benefit to the school environment, and academic engagement among youth [40]. The review of gratitude studies among nonclinical, adolescent populations revealed that study samples consisted predominantly of White non-Hispanic students, along with a smaller proportion of African-American and Hispanic-American students. The empirical evidence for increased gratitude exists, yet researchers called for more interventional studies (see $[26,27,37,41]$ ).

1.3. Global Life Satisfaction. Subjective well-being, or happiness, can be measured in multiple ways. Global life satisfaction, which can be contrasted with satisfaction in different life domains, measures overall contentment with life [15]. Life satisfaction among adolescents living in the US is often measured using Huebner's [42] Students' Life Satisfaction Scale (SLSS). Many recently published studies utilizing the SLSS among American adolescents are documented in the literature. Correlational studies (see [16, 43]), longitudinal analyses (see [14, 17]), and cross-cultural studies (see [44]) have been conducted with US adolescents. Suldo et al.'s [17] longitudinal interventional study tested several assessments, including the SLSS, to measure change over time for 6thgrade students. The aforementioned interventional study found a trend in decreased SLSS among its wait-list control group, but not to a significant degree (SLSS; $F[1,19]=.59$, $\left.p=0.450, \eta^{2}=.03\right)$.

Youth well-being researchers also encouraged additional studies that tested well-being measures such as life satisfaction across varied cultures [45]. The review of life satisfaction studies conducted in school environments among general, nonclinical, adolescent populations revealed that study samples consisted predominantly of White non-Hispanic students and a smaller proportion of African-American and Hispanic-American students.

1.4. School Satisfaction. School satisfaction is a domainspecific assessment of how children and adolescents feel about different characteristics and aspects of school and school experiences $[46,47]$. It is widely accepted within the well-being paradigm that objective measures, such as individual academic performance or aggregated school performance, paint an incomplete picture of a student's academic profile [47]. School satisfaction is equivalent to the emotional aspect of school engagement [14].

The construct of school satisfaction is correlated to several other factors that are both subjective and objective. School satisfaction is correlated to school climate, which encompasses academic support, student-teacher relationship, school connectedness, order, and discipline in school [47]. School satisfaction is correlated also to school-related social support [46]. Longitudinally, school satisfaction predicted positive school behavior and less aggression [48]. Emotional engagement with school experiences and engagement with peers were found to be significantly correlated and mutually reinforcing [14]. The adolescent years before the end of the compulsory education period are critical to studying interventions that could prevent school dropout [14]. School emotional engagement is a key factor related to school dropout [14]. 
1.5. Meditation and Youth. Increased concentration and ability to manage stress among adults proved effective also for children and adolescents who practiced meditation $[49,50]$. Meditation interventions among youth are implemented as school-based, clinic-based, or community-based settings [29, 51]. Meditation helped youth manage behavior, emotions, and thinking skills that are beneficial in the school and the home environment $[28,50]$. Meditation correlated to a decrease in behavioral challenges related to autism spectrum disorders, attention deficit and hyperactivity disorders (ADHD), and bullying [50].

1.5.1. Meditation, Emotional, and Psychosocial Factors. The practice of meditation was proven to positively affect emotional and psychosocial conditions for children and adolescents. A 2009 16-study meta-analysis concluded that meditation was an effective intervention for improving behavioral, psychosocial, and physical conditions among youth 6-18 years old [51]. Behavioral and emotional problems affect different aspects of school, as well as familial relationships. Interventional studies proved that meditation was a useful tool for improving behavioral, emotional, and familial relationship challenges among youth aged nine to 19 [28]. Self-harm is a concern among preadolescent and adolescent populations because of the concerning rates of suicide and attempted suicide in this group [52]. Britton et al.s [52] more recently published clinical trial studied the effects of mindfulness meditation on sixth-grade students living in the US and found a significant decrease in suicide ideations [likelihood ratio $=7.73, p=0.005]$, but differences $\operatorname{did}$ not reach significance for affective and behavioral symptoms between the treatment group and the control group. The aforementioned study was one of the few trials conducted among nonclinical, general youth populations.

1.5.2. Meditation, Behavioral Diagnoses, and School. The practice of meditation was linked to improved clinical diagnoses and improved behaviors which, left untreated, contribute to poor academic performance among school-aged youth [53]. Meditation proved effective with children's executive function skills $[28,53]$. Executive function (EF), defined as a set of processes such as carrying out goal-oriented activities, was shown to play a role in young children's academic abilities. Poor EF, which can manifest as issues with concentration or impulsivity, was associated with behavioral challenges, delinquency, ADHD, and bullying [53]. Executive function was also linked to school adjustment for elementary students transitioning into middle school [54].

The effectiveness of meditation was evaluated by measuring children's self-regulation skills $[50,51,53]$. Self-regulatory behaviors, defined as a set of behaviors that direct and monitor the success of activity, are a subset of EF [55]. Cognitively, certain aspects of EF are related to different dimensions of self-regulation [53]. Further, metareviews demonstrated meditation's effectiveness on self-regulation [28, 53]. Wisner et al.'s [50] review of 11 school-based studies conducted among secondary school students revealed meditation's positive effect on self-regulation and coping abilities.
1.5.3. Meditation Practices. A variety of meditation practices have been studied among adolescents. The majority of school-based meditation interventions documented in the literature were limited to mindfulness meditation (MM) or other mindfulness-related techniques, like mindfulnessbased stress reduction (MBSR) and mindfulness-based cognitive therapy (MBCT), transcendental meditation (TM), and Relaxation Response (RR). Black et al. [51] reviewed MM, MBSR, MBCT, and TM interventions. Wisner et al. [50] examined MM, TM, and RR studies. Harnett and Dawe [28] conducted a review of MM studies published between 2009 and 2012 that included clinical and nonclinical interventional studies conducted among children and adolescents. Waters et al.s [29] review included MM, MBSR, and TM. Further, Waters et al. [29] explored four less frequently studied types of practice: Loving-Kindness meditation, Vipassana meditation, Yoga Nidra meditation, and Centering Prayer meditation. The aforementioned authors' [29] interest in meditation practice for youth stemmed from previous neuroscience findings of the increased plasticity of the brain in the regions that regulate emotional regulation, thereby supporting students' well-being, social competence, and academic achievement.

1.6. Heart-Centered Meditation. The lead author of the current study had 25 years of personal experience practicing and 21 years of experience teaching the heart-centered meditation methods (on a voluntary basis). The aforementioned technique is also known as The Path of the Heart. The heartcentered techniques [56] are a natural approach to increasing gratitude, which is an aim of this study. According to Park and Peterson [57], gratitude is one of the traits of the heart. Authors Park and Peterson [57] developed the Values in Action Inventory of Strengths for Youth (VIA-Y), which is a modified version of the original adult measure. Other strengths of the heart measured in the VIA-Y include hope, love, and zest [57]. To date, this is the first published intervention study utilizing these techniques explicitly; therefore, no previously available comparison data from an interventional study exists.

The intervention implemented in this study is modeled after the techniques in the manual of [34]. Heart-centered meditation is distinguished from mindfulness meditation, described by Kabat-Zinn [58], and transcendental meditation, described by the Maharishi Foundation USA [59]. Mindfulness meditation, typically practiced with the eyes closed, is described as an awareness that comes about as the practitioner focuses on the present moment in a nonjudgmental way [58]. The most common method of practicing transcendental meditation, on the other hand, is by the repetition of a word or sound which enables the practitioner to enter into a deeper silence without the practice of concentration [59]. The prescription, outlined in the source manual for the heart-centered technique [56], is the following: the eyes remain partially opened, while the practitioner focuses the mind with a concentration or a visualization technique. The repetition of a mantra (sound or word) is optional.

The heart-centered technique recommends the practitioner to prepare for meditation first by sitting comfortably, 
TABLE 1: Demographic profile by treatment group.

\begin{tabular}{|c|c|c|c|c|}
\hline & $\begin{array}{c}\text { Control group } \\
N(\%)\end{array}$ & $\begin{array}{c}\text { Treatment group } \\
N(\%)\end{array}$ & $\begin{array}{c}\text { Total cohort } \\
N(\%)\end{array}$ & $\begin{array}{l}\text { Statistic } \\
p \text { value }\end{array}$ \\
\hline \multicolumn{5}{|l|}{ Gender } \\
\hline Female & $15(60.0 \%)$ & $17(56.7 \%)$ & $32(58.2 \%)$ & \multirow{3}{*}{$\begin{array}{c}\chi^{2} \\
p=0.803\end{array}$} \\
\hline Male & $10(40.0 \%)$ & $13(43.3 \%)$ & $23(41.8 \%)$ & \\
\hline Total & $25(45.5 \%)$ & $30(54.5 \%)$ & $55(100.0 \%)$ & \\
\hline \multicolumn{5}{|l|}{ Grade level } \\
\hline 6th & $12(48.0 \%)$ & $12(40.0 \%)$ & $24(43.6 \%)$ & \multirow{3}{*}{$\begin{array}{c}\text { Cramer's V } \\
p=0.824\end{array}$} \\
\hline 7 th & $9(36.0 \%)$ & $13(43.3 \%)$ & $22(40.0 \%)$ & \\
\hline 8th & $4(16.0 \%)$ & $5(16.7 \%)$ & $9(16.4 \%)$ & \\
\hline \multicolumn{5}{|l|}{ Ethnic background } \\
\hline African-Ämerican & $13(52.0 \%)$ & $21(70.0 \%)$ & $34(61.8 \%)$ & \multirow{3}{*}{$\begin{array}{c}\text { Cramer's } V \\
p<0.05\end{array}$} \\
\hline Caribbean-American & $4(16.0 \%)$ & $8(26.7 \%)$ & $12(21.8 \%)$ & \\
\hline Multi/other/Hispanic & $8(32.0 \%)$ & $1(3.3 \%)$ & $9(16.4 \%)$ & \\
\hline \multirow{3}{*}{$\begin{array}{l}\text { Ethnic background } \\
\text { African-American } \\
\text { Other ethnicities }\end{array}$} & & & & \multirow{3}{*}{$\begin{array}{c}\text { Fischer's Exact } \\
\qquad p=0.265\end{array}$} \\
\hline & $13(52.0 \%)$ & $21(70.0 \%)$ & $34(61.8 \%)$ & \\
\hline & $12(48.0 \%)$ & $8(30.0 \%)$ & $12(38.2 \%)$ & \\
\hline
\end{tabular}

relaxing the body, and quieting the mind with a breathing exercise [56]. The meditation practice continues with a concentration exercise or a visualization exercise. The practitioner tries to keep the mind quiet, by clearing the mind of as many thoughts as possible. As described by Chinmoy [56],

There is a vast difference between what you can get from the mind and what you can get from the heart. The mind is limited; the heart is unlimited. Deep within you are infinite peace, light and bliss. To get a limited quantity is an easy task. Meditation in the mind can give it to you. But you can get infinitely more if you meditate in the heart. (p. 52)

\section{Materials and Methods}

2.1. Population. This intervention was conducted among a cohort of middle school students attending a K-8 public charter school, located in a low-income urban region of Metropolitan Miami. A total of 75 students were actively enrolled in the middle school at the start of the study. The school was approached for several reasons: ethnic diversity of the student body and convenience of location, and no similar study nor intervention had been conducted among this group of students. Sixty-eight students consented. No students were denied participation in the study, but prior to data analyses, the data of students receiving special needs services, as identified by school administrators, and incomplete records were eliminated from the data analyses. The final cohort available for data analysis was 55. The detailed profile of the final cohort is depicted in Table 1.

\subsection{Permission, Face-Validation, Consent, and Randomiza-} tion. Site permission was obtained from the school principal, and full-board approval was granted by a university Institutional Review Board (IRB). Permission was granted by the Sri Chinmoy Centres International, owner of the rights to the manuals used in the intervention (see $[34,56]$ ), to use the techniques for research and academic purposes. The lead author was the onsite researcher who conducted the full consent and assent process and the implementation of the intervention. Both consent (parent or guardian) and assent (child) were obtained. Three students belonging to a group of students not invited for participation and two research experts were consulted to face-validate the researcher-created forms. A master list of student identification numbers was numbered, computerized, and sorted. The toss of a coin determined whether the first student on the list would be assigned to the control or treatment group.

2.3. Instrumentation. Three existing instruments and two researcher-designed data collection forms were administered in the study. The preexisting instruments were chosen to collect participants' pretest and posttest life satisfaction, school satisfaction, and measured gratitude. A demographic questionnaire was created to capture basic demographic information, prior experience with meditation ("no experience," "practiced a few times," and "practiced many times"), and prior experience with gratitude.

To avoid confusion with casual expressions of thankfulness, the gratitude experience question was stated as: "Do you focus on feeling grateful-while praying, during moments of silence, during meditation, or other activities-either alone, with family, or in your place of worship?" Responses were "never do," "sometimes do," or "very often." A practice log captured at-home practice for the treatment group only and a life stressor question, which both study groups responded to.

2.3.1. Life Satisfaction Measure. Life satisfaction was evaluated both at pretest and at posttest. Huebner's [42] Students' Life Satisfaction Scale (SLSS) measured general, global life satisfaction. The SLSS, a relatively short, seven-question scale, exhibited high internal consistency (alpha $=0.82-0.88$ ), not 
only for one-time use but also for test-retest reliability at 1-2 weeks $(r=.074)$ [42]. Using the SLSS, students replied with six-point Likert-type responses $(1=$ strongly disagree $\cdots 6=$ strongly agree) to statements such as "My life is going well."

2.3.2. School Satisfaction Measure. Participants' satisfaction with school was evaluated before and after the intervention, utilizing the School Satisfaction Subscale (SSS) of the Multidimensional Students' Life Satisfaction Scale (MSLSS) by Huebner [60]. The 40-item MSLSS measures satisfaction among children and adolescents in five life domains: family, friends, living environment, self, and school; however, the individual domains are valid as stand-alone subscales [60, 61]. The internal consistency of the eight-question SSS was reported at the minimum of 0.70 (e.g., [46, 47, 61, 62]). Similar to the SLSS, students responded with six-point Likerttype responses ( $1=$ strongly disagree $)$ to SSS questions such as "I like being in school."

2.3.3. Gratitude Measure. Participant's level of gratitude was measured both at pretest and at posttest. The Gratitude Questionnaire-Six-Item Form (GQ-6), validated for adults and youth (see $[63,64]$ ), was administered to measure a grateful disposition. McCullough et al's GQ-6 [64] reported good internal consistency for the GQ-6 among children and adolescents 10 to 19 . More recently, Froh et al. [63] demonstrated internal consistency at 0.59 for 10 - to 12 -yearolds, 0.45 for 12 - to 13 -year-olds, and 0.70 for 14 - to 19 -yearolds. According to McCullough et al. [65], the one-year testretest reliability of the GQ-6 suggests that the GQ-6 is a stable measure of the gratitude disposition. The GQ-6 questions, that is, "I have so much in life to be thankful for," were scored with seven-point Likert-type responses ( 1 = strongly disagree $\cdots 4=$ neutral $\cdots 7$ = strongly agree).

2.3.4. Demographic Questionnaire and Practice Log. Two researcher-created forms, The Socio-Demographic Questionnaire and The Weekly Practice Log captured demographic information and other study-related data, respectively. Data were evaluated as possible study confounders. The demographic form included participants' gender, grade level, ethnicity, and previous experience with meditation and gratitude, whereas the practice log captured practice history as well as the occurrence of significant life stressor(s).

2.4. The Intervention. For 10 sessions, lasting between 15 and 20 minutes, participants randomized to the treatment group were instructed breathing and relaxation exercises, concentration techniques, and visualization techniques. Utilizing a variety of objects to focus on, including a dot within a circle, a flower, or an artificial candle flame, participants practiced different concentration techniques. Most visualizations were designed to invoke the quality of gratitude. During each session, the treatment group also repeated in unison one or more aphoristic poems on the themes of peace or serenity, quieting the thoughts, and gratitude. The treatment group was encouraged to practice at home in between study sessions. Attendance was taken for the control group, either before or after each of the 10 intervention sessions; the control group was then dismissed. The delayed intervention, no-treatment control group received an abridged version of the exercises after posttest data was collected for both groups.

\section{Results and Discussion}

3.1. Analyses and Results. Univariate statistics described the cohort. Participants were randomly assigned to study groups, but due to attrition, study groups were examined for significant differences. Variables that differed significantly by study group qualified for entry into the ANCOVA models as extraneous or confounding variables. Pretest variables were assigned as covariates; three ANCOVA models tested the main effect of the intervention on posttest life satisfaction, school satisfaction, and measured gratitude-comparing the treatment group to the control group.

3.1.1. Cohort Description. A total of 68 mixed-gender, 6ththrough 8th-grade middle school students consented for participation. Students were randomized evenly either to the control group $(N=34)$ or to the treatment group $(N=34)$. Due to participant attrition and records that did not meet the inclusion criteria (lower than 50\% attendance; receiving special needs services; incomplete responses), 55 records remained in the final study data set-25 controls and 30 in the treatment group (Table 1).

As tabulated in Table 1, a slightly larger proportion of participants were female (58\%). The participants were nearly evenly distributed in the two lower grades, 6th (44\%) and 7th (40\%) grades, respectively, but a much smaller proportion attended the 8 th-grade graduating class (16\%). Participants were minorities, predominantly of American heritage. Most participants self-identified as African-American (62\%). The remainder self-identified as Caribbean-American (22\%), multiethnic and other minorities (13\%), or HispanicAmerican (4\%). No participants self-identified as WhiteAmerican (white race, predominantly of American heritage).

Nearly half of the participants endorsed some or frequent experience with meditation (49\%); conversely, very few participants endorsed never practicing gratitude (5\%). A higher proportion than what was expected endorsed frequent practice of meditation (24\%), invoking gratitude (38\%), and a stressful life event during the study (47\%), as shown in Table 1.

3.1.2. Bivariate Analyses by Study Group. Demographic characteristics and study-related characteristics were analyzed to test group differences, prior to constructing the ANCOVA models. Statistically significant differences would warrant the inclusion of those variables as extraneous or confounder variables into the ANCOVA tests. The appropriate chi-square for $2 \times 2$ tables, Fisher's Exact for $3 \times 2$ tables, or Cramer's V, to accommodate for low-frequency cells, were executed.

Slight differences emerged for the demographic characteristics by study group. There were a slightly higher proportion of female students in the control group (60\%) compared to the treatment group (57\%) and 6th-grade students in the control group (48\%) compared to the treatment group (40\%). A higher proportion of African-American students (70\%) 
TABLE 2: Participants' study-related characteristics by treatment group.

\begin{tabular}{|c|c|c|c|c|}
\hline Characteristic & $\begin{array}{c}\text { Control group } \\
N(\%)\end{array}$ & $\begin{array}{c}\text { Treatment group } \\
N(\%)\end{array}$ & $\begin{array}{c}\text { Total cohort } \\
N(\%)\end{array}$ & $\begin{array}{l}\text { Statistic } \\
p \text { value }\end{array}$ \\
\hline \multicolumn{5}{|c|}{ Meditation experience (prior-all levels) } \\
\hline No experience & $16(64.0 \%)$ & $12(40.0 \%)$ & $28(50.9 \%)$ & \multirow{3}{*}{$\begin{array}{c}\text { Cramer's V } \\
p<0.05\end{array}$} \\
\hline Few times & $7(28.0 \%)$ & $7(23.3 \%)$ & $14(25.5 \%)$ & \\
\hline Many times & $2(0.8 \%)$ & $11(36.7 \%)$ & $13(23.6 \%)$ & \\
\hline \multicolumn{4}{|c|}{ Meditation experience (prior-collapsed) } & \multirow{3}{*}{$\begin{array}{c}\text { Fischer's Exact } \\
p=0.106\end{array}$} \\
\hline No experience & $16(64.0 \%)$ & $12(40.0 \%)$ & $28(50.9 \%)$ & \\
\hline Some experience & $9(36.0 \%)$ & $18(60.0 \%)$ & $27(49.1 \%)$ & \\
\hline \multicolumn{5}{|c|}{ Experience invoking gratitude (prior) } \\
\hline Never do & $2(8.0 \%)$ & $1(3.3 \%)$ & $3(5.4 \%)$ & \multirow{3}{*}{$\begin{array}{c}\text { Cramer's V } \\
p=0.691\end{array}$} \\
\hline Sometimes I do & $13(52.0 \%)$ & $18(60.0 \%)$ & $31(56.4 \%)$ & \\
\hline Very often & $10(40.0 \%)$ & $11(36.7 \%)$ & $21(38.2 \%)$ & \\
\hline \multicolumn{4}{|c|}{ Gratitude experience (prior-collapsed) } & \multirow{3}{*}{$\begin{array}{c}\text { Fischer's Exact } \\
\quad p=1.00\end{array}$} \\
\hline Never/sometimes & $13(60.0 \%)$ & $19(63.3 \%)$ & $34(61.8 \%)$ & \\
\hline Very often & $10(40.0 \%)$ & $11(36.7 \%)$ & $21(38.2 \%)$ & \\
\hline \multicolumn{4}{|c|}{ Intervention practice frequency (collapsed) } & \multirow{5}{*}{$\begin{array}{c}\text { Descriptive } \\
\text { Min }=3 \\
\text { Max }=41 \\
\text { Median }=11\end{array}$} \\
\hline$\leq 6$ times & - & $7(23.3 \%)$ & - & \\
\hline $7-10$ times & - & $7(23.3 \%)$ & - & \\
\hline 11-14 times & - & $7(23.3 \%)$ & - & \\
\hline$\geq 15$ times & - & $9(30.0 \%)$ & - & \\
\hline \multicolumn{4}{|c|}{ Stressful life event (during the study) } & \multirow{3}{*}{$\begin{array}{c}\text { Fisher's Exact } \\
p=0.058\end{array}$} \\
\hline No & $17(68 \%)$ & $12(40 \%)$ & $29(52.7 \%)$ & \\
\hline Yes & $8(32 \%)$ & $18(60 \%)$ & $26(47.3 \%)$ & \\
\hline
\end{tabular}

remained in the treatment group, compared to the control group (52\%). Despite the differing proportions, no statistically significant differences were detected, as demonstrated in Table 1.

Other study-related characteristics were analyzed as well (see Table 2). To accommodate for low-frequency responses and facilitate more meaningful comparisons, levels of meditation and gratitude were collapsed. Both the original and the collapsed variables were tested. A higher proportion of the treatment group endorsed some experience with meditation (60\% versus $36 \%$ ) but invoked gratitude slightly less often (37\% versus $40 \%$ ). Neither experience with meditation $(p=0.106)$ nor experience invoking gratitude $(p=1.00)$ differed significantly. A higher proportion of the treatment group (60\% versus $32 \%)$ reported a stressful life event. The treatment group's at-home practice totals were examined. The treatment group practiced with a median of 11 times during the intervention (range: 3,41). Summaries are tabulated in Table 2. Despite uneven distributions of participants' demographic (Table 2) and other study characteristics (Table 3) among those who remained in the final cohort, no statistically significant differences emerged by study group.

Unadjusted mean school satisfaction, life satisfaction, and gratitude were calculated for study groups at pretest and posttest (see Table 3). Groups were essentially the same at pretest for school satisfaction (35.5 versus $35.3, p=n s$ ), life satisfaction (28.0 versus $29.6, p=n s$ ), and gratitude
(32.4 versus 32.7, $p=n s$ ); no significant differences were detected by $t$-test. After intervention, study groups differed significantly for the outcome variables. Group mean posttest scores differed by a minimum of 4 points, as evidenced in Table 3, before adjusting for the corresponding pretest scores. Significant differences indicated trends towards increased posttest scores, but the ANCOVA test was executed to establish causality of the intervention upon mean posttest scores.

3.1.3. ANCOVA Models. The results from the G-power software analysis [66] for ANCOVA yielded that a minimum of 52 participants were needed to detect a large effect size $(f=$ 0.4 ), with $80 \%$ power, and 0.05 cutoff for significance and adjusted for a maximum of five covariates. Three ANCOVA models tested posttest life satisfaction, school satisfaction, and gratitude using the corresponding pretest scores as covariates (Table 4). As no significant differences emerged by study group when tested with bivariate analyses, the ANCOVA models were restricted to testing the differences between the control group and the treatment without any confounders entered into the models. The four core assumptions of normality of distribution, homogeneity of variances, independence of variables, and linearity of the covariate to dependent variable were tested systematically prior to executing the ANCOVA test. Significance levels were set to 0.05 (95\% confidence interval). Normality of distribution does not 
TABLE 3: Unadjusted mean pretest and posttest scores by treatment group.

\begin{tabular}{|c|c|c|c|c|}
\hline Measure & $\begin{array}{c}\text { Pretest } \\
\text { mean }\end{array}$ & $\begin{array}{c}\text { Statistic } \pm S D \\
p \text { value }\end{array}$ & $\begin{array}{c}\text { Posttest } \\
\text { mean }\end{array}$ & $\begin{array}{c}\text { Statistic } \pm \text { SD } \\
p \text { value }\end{array}$ \\
\hline \multicolumn{5}{|c|}{ School satisfaction (MSLSS-SS) } \\
\hline Control group & 35.5 & 6.3 & 34.2 & 7.9 \\
\hline \multirow[t]{2}{*}{ Treatment group } & 35.3 & 5.1 & 39.7 & 5.8 \\
\hline & & $p=\mathrm{ns}$ & & $p=0.005$ \\
\hline \multicolumn{5}{|l|}{ Life satisfaction (SLSS) } \\
\hline Control group & 28.0 & 7.4 & 26.6 & 7.6 \\
\hline \multirow[t]{2}{*}{ Treatment group } & 29.6 & 6.5 & 31.2 & 6.7 \\
\hline & & $p=\mathrm{ns}$ & & $p=0.020$ \\
\hline \multicolumn{5}{|l|}{ Gratitude (GQ-6) } \\
\hline Control group & 32.4 & 7.0 & 29.6 & 9.1 \\
\hline \multirow[t]{2}{*}{ Treatment group } & 32.7 & 5.8 & 36.7 & 3.9 \\
\hline & & $p=\mathrm{ns}$ & & $p=0.001$ \\
\hline
\end{tabular}

TABLE 4: ANCOVA results of the main effect on posttest scores, adjusted for pretest scores.

\begin{tabular}{|c|c|c|c|c|c|c|}
\hline $\begin{array}{l}\text { Posttest score } \\
\text { Study group }\end{array}$ & $n$ & $\begin{array}{c}\text { Levene's test of equal } \\
\text { variance }\end{array}$ & Group mean & Adjusted mean & $\begin{array}{l}\text { Main effect } \\
\text { ( } p \text { value })\end{array}$ & $\begin{array}{c}\text { Partial } \eta^{2} \\
R^{2} \\
\text { Adj. } R^{2}\end{array}$ \\
\hline School satisfaction & & & & & & 0.185 \\
\hline Control & 25 & & 34.3 & $34.2 \pm 1.2$ & & 0.362 \\
\hline Treatment & 30 & $p=0.714$ & 39.7 & $39.8 \pm 1.1$ & $p=0.001$ & 0.338 \\
\hline Life satisfaction & & & & & & 0.104 \\
\hline Control & 25 & & 26.6 & $27.2 \pm 1.0$ & & 0.544 \\
\hline Treatment & 30 & $p=0.802$ & 31.2 & $30.7 \pm 0.9$ & $p=0.017$ & 0.527 \\
\hline Gratitude & & & & & & 0.243 \\
\hline Control & 25 & & 29.6 & $29.7 \pm 1.3$ & & 0.349 \\
\hline Treatment & 30 & $p=0.101$ & 36.7 & $36.6 \pm 1.1$ & $p<0.001$ & 0.324 \\
\hline
\end{tabular}

have to be strictly adhered to, provided distributions are fairly normal $[67,68]$. While slight irregularities were observed in distribution, the ANCOVA models met the four assumptions.

Life Satisfaction. Posttest life satisfaction was tested with the first ANCOVA. A slight irregularity was detected in the posttest life satisfaction distribution, but distribution was relatively normal on visual inspection, as explained in [67, 68]. After controlling for participants' pretest life satisfaction, a statistically significant difference for posttest life satisfaction was detected ( $p=0.017$ ). The null hypothesis was rejected. The partial $\eta^{2}$ was 0.104 , indicating a medium effect size on life satisfaction. ANCOVA tests for the outcome variables are listed in Table 4.

School Satisfaction. A difference in posttest school satisfaction was tested with the second ANCOVA test. After controlling for participants' pretest school satisfaction scores, a statistically significant difference was detected for the intervention's effect on posttest school satisfaction $(p=0.001)$. The null hypothesis was rejected. The partial $\eta^{2}$ of 0.185 indicated a large effect size for posttest school satisfaction.
Gratitude. A difference in measured gratitude was tested in the third ANCOVA. Similar to the findings in the test of assumptions for posttest life satisfaction, a slight irregularity in the gratitude distribution was detected; however, the distribution was relatively normal on visual inspection. After controlling for participants' pretest gratitude, a statistically significant difference at posttest was detected $(p<0.001)$. The null hypothesis was rejected. The partial $\eta^{2}$ of 0.243 indicated a large effect size, mirroring the magnitude of school satisfaction.

3.2. Discussion. Based on the population data assembled by national and international epidemiological institutes, including the CDC and the WHO, as many as one in three adolescents face a myriad of psychological and mental health challenges such as depression and attempted suicide. These challenges follow adolescents into young adulthood and adulthood-for those who make it to adulthood, as the CDC and the WHO reported suicide as the third leading cause of death among adolescents. Interventions based on the positive psychology paradigm take a strengths-based approach to increasing youth attributes such an optimistic outlook and a 
grateful disposition-shown to prevent future psychological diagnoses and mental illness. Gratitude interventions are the most researched positive psychology interventions. The positive interrelatedness between subjective well-being, or happiness, and gratitude, as well as academic outcomes and school engagement, is documented in the US, but study populations were limited in cultural diversity. The secular practice of meditation, initially studied among clinical youth populations for its physiological, psychological, and behavioral benefits, is studied increasingly among general, nonclinical populations as a viable method for increasing well-being and academically related outcomes. The purpose of this study was to test a novel positive psychology intervention that included the secular practice of meditation that was combined with gratitude visualizations and tested among a culturally diverse cohort of adolescents living in the US.

The majority of participants of this 4-week study attended the 6 th $(44 \%)$ and 7 th $(40 \%)$ grade, respectively, and self-identified as African-American (62\%) or CaribbeanAmerican (22\%). A slightly larger proportion of participants were female $(58 \%)$. At baseline, a higher proportion than what was expected endorsed the frequent practice of meditation $(24 \%)$ and invoked gratitude (38\%). After intervention, nearly half of the participants $(47 \%)$ reported a stressful life event had occurred during the study period. Despite the slight characteristic differences by study group, significance testing demonstrated these differences were nonsignificant (see Table 1).

Participants randomized to the treatment group appeared to tolerate the intervention well. The lead author, who was the onsite researcher and interventionist, observed that the students seemed to benefit from the exercises and enjoyed the sessions. Even stronger anecdotal evidence was provided by the lead middle school instructor and the lead school administrator, both of whom shared positive feedback regarding their observations. Both school personnel commented on the ability of students in the treatment group to better selfregulate and remain more on task with their schoolwork.

One interesting note is that the lead author experienced a construct validity issue with the variables that captured prior history of practicing meditation and prior history of invoking gratitude. Although the students progressed through the session, their slower response to the intervention after the first two or three sessions was incongruent to the proportion who endorsed at least some previous experience with practicing "meditation" (49\%) and the practice of "gratitude" exercises often (38\%). In addition, it is possible that participants' meditation and gratitude endorsements represented religious practices of quiet time in church, or "giving thanks" at meal times, rather than the focused practices instructed during intervention sessions. In bivariate comparisons, the two study groups did not differ significantly; therefore, additional adjustments were not required for the ANCOVA tests (see Tables 2 and 3 ).

Three ANCOVA models tested the effectiveness of the intervention on participants' posttest school satisfaction, life satisfaction, and gratitude, while controlling for the corresponding pretest score. No other variables met criteria for inclusion into the ANCOVA models. Statistically significant differences were detected. As depicted by partial $\eta^{2}$ results in Table 4, the magnitude of the difference for school satisfaction and gratitude was large, and the magnitude of the difference was medium for life satisfaction.

\section{Conclusion}

This study demonstrated that a 4-week gratitude-meditation intervention conducted among a cohort of ethnically diverse middle school students living in Metropolitan Miami increased significantly happiness, emotional engagement with school, and measured gratitude. Pretest-posttest comparisons of the treatment group to the control group were significant for the main effect of all three outcomes.

Several factors limited the generalizability of the study's findings to larger populations. The study was limited by the factors inherent to the quasi-experimental study design, by the convenience sampling method, and by the length of time the study was conducted. The $\mathrm{G}^{*}$ Power analysis [66] dictated that 52 cases (26 in each group) were needed to detect a large effect size for the ANCOVA. While the final cohort of 55 exceeded the minimum requirement, the study sample was not a true representative of ethnically diverse adolescents in the region. Also, it was not possible to analyze statistically more complex relationships among the participants' characteristics and outcome variables with a cohort of 55 participants. Despite these limitations to the study's generalizability, this study contributed to the study of subjective wellbeing and positive psychology in several ways, particularly for adolescent populations. First, this study was unique in that no similar, recently published (six years) interventional studies conducted among general adolescent populations living in the US were found in the literature. Second, this study contributed to the academic literature regarding the use of subjective well-being and positive psychology measures among diverse cultural youth populations living in the US. Third, no study fused the practice of gratitude and meditation together as one intervention. Finally, no study examined the effect of gratitude or meditation upon school satisfaction, life satisfaction, and gratitude in one intervention.

Compared to other gratitude and life satisfaction interventional studies conducted among adolescents in the literature, this study's main effect fared better from a statistical perspective. Froh et al. [39] reported a small effect size for increased gratitude at eight days and 3 weeks, no significant difference for the positive affect of well-being, and a small effect size for decreased negative affect. Froh et al. [27] detected no significant difference for increased gratitude among 3rd, 8th, and 12th graders in their study. More recently, Froh et al. [37] reported a small effect size for their longitudinal study of a gratitude curriculum taught to youth aged eight to 11 years. The medium (life satisfaction) to large effect (school satisfaction and gratitude) we detected suggests that the study yielded statistically more effective results.

The study highlights the importance of continued testing of well-being measures among adolescents, and the importance of continued research of positive psychology interventions, particularly among ethnic minority populations. The study also highlights the importance of continued research 
examining the secular practice of meditation among schoolaged adolescents. The findings suggest further studies are needed to test this novel intervention on larger study cohorts among both ethnic minority and ethnic majority adolescents, older and younger adolescents who represent other cultural groups, and as a longitudinal study. Some have suggested that happiness and meditation, independently, should be taught in schools [69]. This study begs the question of whether happiness, meditation, and gratitude should be taught in schools.

\section{Conflicts of Interest}

The authors declare that there are no conflicts of interest regarding the publication of this paper.

\section{References}

[1] World Health Organization (WHO), "Mental health: Maternal and child mental health,” 2016, http://www.who.int/mental_ health/maternal-child/en/.

[2] World Health Organization (WHO), "WHO calls for stronger focus on adolescent health," 2014, http://www.who.int/mediacentre/news/releases/2014/focus-adolescent-health/en/.

[3] Child Trends Databank, "Adolescents who felt sad or hopeless," 2014, http://www.childtrends.org/?indicators=adolescents-whofelt-sad-or-hopeless.

[4] Federal Interagency Forum on Child and Family Statistics, "America's children: Key national indicators of well-being, 2013," Washington, DC: U.S. Government Printing Office, 2013, http://www.childstats.gov/pdf/ac2013/ac_13.pdf.

[5] N. Jiang, L. J. Kolbe, D.-C. Seo, N. S. Kay, and C. D. Brindis, "Health of adolescents and young adults: Trends in achieving the 21 critical national health objectives by 2010," Journal of Adolescent Health, vol. 49, no. 2, pp. 124-132, 2011.

[6] R. W. Larson, "Positive development in a disorderly world," Journal of Research on Adolescence, vol. 21, no. 2, pp. 317-334, 2011.

[7] J. S. Eccles and R. W. Roeser, "Schools as developmental contexts during adolescence," Journal of Research on Adolescence, vol. 21, pp. 225-241, 2011.

[8] Centers for Disease Control and Prevention (CDC), "Adolescent and school health: Health \& academics," 2016, http://www .cdc.gov/HealthyYouth/health_and_academics/index.htm.

[9] C. Proctor, "Child and adolescent life satisfaction," in Encyclopedia of Quality of Life and Well-Being Research, A. C. Michalos, Ed., pp. 663-672, Springer, Dordrecht, The Netherlands, 2014.

[10] L. T. Hoyt, P. L. Chase-Lansdale, T. W. McDade, and E. K. Adam, "Positive youth, healthy adults: Does positive well-being in adolescence predict better perceived health and fewer risky health behaviors in young adulthood?" Journal of Adolescent Health, vol. 50, no. 1, pp. 66-73, 2012.

[11] A. Shoshani and S. Steinmetz, "Positive psychology at school: A school-based intervention to promote adolescents mental health and well-being," Journal of Happiness Studies, vol. 15, pp. 1289-1311, 2013.

[12] S. Marques, J. J. Pais-Ribeiro, and S. Lopez, "The role of positive psychology constructs in predicting mental health and academic achievement in children and adolescents: A two-year longitudinal study," Journal of Happiness Studies, vol. 12, pp. 1049-1062, 2011.
[13] A. Shoshani and M. Slone, "Middle School Transition from the Strengths Perspective: Young Adolescents' Character Strengths, Subjective Well-Being, and School Adjustment," Journal of Happiness Studies, vol. 14, no. 4, pp. 1163-1181, 2013.

[14] A. D. Lewis, E. Huebner, P. S. Malone, and R. F. Valois, "Life satisfaction and student engagement in adolescents," Journal of Youth and Adolescence, vol. 40, pp. 249-262, 2011.

[15] S. M. Suldo, A. Thalji-Raitano, M. Hasemeyer, C. D. Gelley, and B. Hoy, "Understanding Middle School Students Life Satisfaction: Does School Climate Matter?" Applied Research in Quality of Life, vol. 8, no. 2, pp. 169-182, 2013.

[16] S. P. Antaramian, E. S. Huebner, K. J. Hills, and R. F. Valois, "A dual-factor model of mental health: Toward a more comprehensive understanding of youth functioning," The American Journal of Orthopsychiatry, vol. 80, pp. 462-472, 2010.

[17] S. M. Suldo, J. A. Savage, and S. H. Mercer, "Increasing Middle School Students' Life Satisfaction: Efficacy of a Positive Psychology Group Intervention," Journal of Happiness Studies, vol. 15, pp. 19-42, 2013.

[18] E. Oberle, K. A. Schonert-Reichl, and B. D. Zumbo, "Life satisfaction in early adolescence: Personal, neighborhood, school, family, and peer influences," Journal of Youth and Adolescence, vol. 40, no. 7, pp. 889-901, 2011.

[19] M. E. P. Seligman, Authentic Happiness: Using the New Positive Psychology to Realize Your Potential for Lasting Fulfillment, Free Press, New York, NY, USA, 2002.

[20] J. Bird and R. Markle, "Subjective well-being in school environments: Promoting positive youth development through evidence-based assessment and intervention," The American Journal of Orthopsychiatry, vol. 82, pp. 61-66, 2012.

[21] J. M. Norrish and D. A. Vella-Brodrick, "Positive psychology and adolescents: Where are we now? Where to from here?" Australian Psychologist, vol. 44, no. 4, pp. 270-278, 2009.

[22] M. E. P. Seligman and M. Csikszentmihalyi, "Positive psychology: An introduction,” American Psychologist, vol. 55, pp. 5-14, 2000.

[23] M. E. P. Seligman, R. M. Ernst, J. Gillham, K. Reivich, and M. Linkins, "Positive education: Positive psychology and classroom interventions," Oxford Review of Education, vol. 35, no. 3, pp. 293-311, 2009.

[24] J. M. Norrish, P. Williams, M. O'Connor, and J. Robinson, “An applied framework for positive education," International Journal of Wellbeing, vol. 3, pp. 147-161, 2013.

[25] L. Bolier, M. Haverman, G. J. Westerhof, H. Riper, F. Smit, and E. Bohlmeijer, "Positive psychology interventions: a meta-analysis of randomized controlled studies," BMC Public Health, vol. 13, no. 119, pp. 1-20, 2013.

[26] M. Krakauer, D. Ruscio, J. Froh, and G. Bono, "Integrating positive psychology and gratitude to work in schools," in Handbook of Australian School Psychology, pp. 691-706, Springer International Publishing, 2017.

[27] J. J. Froh, T. B. Kashdan, K. M. Ozimkowski, and N. Miller, "Who benefits the most from a gratitude intervention in children and adolescents? Examining positive affect as a moderator," The Journal of Positive Psychology, vol. 4, no. 5, pp. 408-422, 2009.

[28] P. H. Harnett and S. Dawe, "The contribution of mindfulnessbased therapies for children and families and proposed conceptual integration," Child Adolescent Mental Health, vol. 17, pp. 195-208, 2012. 
[29] L. Waters, A. Barsky, A. Ridd, and K. Allen, "Contemplative Education: A Systematic, Evidence-Based Review of the effect of Meditation Interventions in Schools," Educational Psychology Review, vol. 27, pp. 103-134, 2014.

[30] F. A. Huppert and D. M. Johnson, "A controlled trial of mindfulness training in schools: The importance of practice for an impact on well-being," The Journal of Positive Psychology, vol. 5, pp. 264-274, 2010.

[31] N. Lau and M. Hue, "Preliminary outcomes of a mindfulnessbased programme for Hong Kong adolescents in schools: Wellbeing, stress and depressive symptoms," International Journal of Children's Spirituality, vol. 16, pp. 315-330, 2011.

[32] T. Mendelson, M. T. Greenberg, J. K. Dariotis, L. F. Gould, B. L. Rhoades, and P. J. Leaf, "Feasibility and preliminary outcomes of a school-based mindfulness intervention for urban youth," Journal of Abnormal Child Psychology, vol. 38, no. 7, pp. 985994, 2010.

[33] R. Davidson, J. Dunne, J. S. Eccles et al., "Contemplative practices and mental training: prospects for American education," Child Development Perspectives, vol. 6, no. 2, pp. 146-153, 2012.

[34] S. Chinmoy, The Jewels of Happiness: Inspiration and Wisdom to Guide Your Life-Journey, Watkins Publishing, London, UK, 2010.

[35] N. Park and C. Peterson, "Character strengths and happiness among young children: Content analysis of parental descriptions," Journal of Happiness Studies, vol. 7, pp. 323-341, 2006.

[36] J. J. Froh, R. A. Emmons, N. A. Card, G. Bono, and J. A. Wilson, "Gratitude and the reduced costs of materialism in adolescents," Journal of Happiness Studies, vol. 12, pp. 289-302, 2011.

[37] J. J. Froh, G. Bono, J. Fan et al., "Nice thinking! An educational intervention that teaches children to think gratefully," School Psychology Review, vol. 43, no. 2, pp. 132-152, 2014.

[38] J. J. Froh, G. Bono, and R. Emmons, "Being grateful is beyond good manners: Gratitude and motivation to contribute to society among early adolescents," Motivation and Emotion, vol. 34, no. 2, pp. 144-157, 2010.

[39] J. J. Froh, W. J. Sefick, and R. A. Emmons, "Counting blessings in early adolescents: An experimental study of gratitude and subjective well-being," Journal of School Psychology, vol. 46, no. 2, pp. 213-233, 2008.

[40] J. J. Froh and G. Bono, "Gratitude in youth: A review of gratitude interventions and some ideas for applications," Communique, vol. 39, no. 5, pp. 1-28, 2011.

[41] J. J. Froh, C. Yurkewicz, and T. B. Kashdan, "Gratitude and subjective well-being in early adolescence: Examining gender differences," Journal of Adolescence, vol. 32, no. 3, pp. 633-650, 2009.

[42] E. S. Huebner, "Initial Development of the Student's Life Satisfaction Scale," School Psychology International, vol. 12, no. 3, pp. 231-240, 1991.

[43] A. M. Chappel, S. M. Suldo, and J. A. Ogg, "Associations between adolescents' family stressors and life satisfaction," Journal of Child and Family Studies, vol. 23, no. 1, pp. 76-84, 2014.

[44] Y. L. Ferguson, T. Kasser, and S. Jahng, "Differences in life satisfaction and school satisfaction among adolescents from three nations: The role of perceived autonomy support," Journal of Research on Adolescence, vol. 21, no. 3, pp. 649-661, 2011.

[45] C. Proctor, A. Linley, and J. Maltby, "Youth life satisfaction: A review of the literature," Journal of Happiness Studies, vol. 10, no. 5, pp. 583-630, 2009.
[46] X. Jiang, E. S. Huebner, and J. Siddall, "A short-term longitudinal study of differential sources of school-related social support and adolescents' school satisfaction," Social Indicators Research, vol. 114, pp. 1073-1086, 2013.

[47] K. J. Zullig, E. S. Huebner, and J. M. Patton, "Relationships among school climate domains and school satisfaction," Psychology in the Schools, vol. 48, pp. 133-145, 2011.

[48] G. M. Elmore and E. S. Huebner, "Adolescents' satisfaction with school experiences: Relationships with demographics, attachment relationships, and school engagement behavior," Psychology in the Schools, vol. 47, no. 6, pp. 525-537, 2010.

[49] C. Burke, "Mindfulness-based approaches with children and adolescents: A preliminary review of current research in an emergent field," Journal of Child Family Studies, vol. 19, pp. 133$144,2009$.

[50] B. L. Wisner, B. Jones, and D. Gwin, "School-based meditation practices for adolescents: A resource for strengthening selfregulation, emotional coping, and self-esteem," Children and Schools, vol. 32, no. 3, pp. 150-159, 2010.

[51] D. S. Black, J. Milam, and S. Sussman, "Sitting-meditation interventions among youth: A review of treatment efficacy," Pediatrics, vol. 124, no. 3, pp. e532-e541, 2009.

[52] W. B. Britton, N. E. Lepp, H. F. Niles, T. Rocha, N. E. Fisher, and J. S. Gold, "A randomized controlled pilot trial of classroombased mindfulness meditation compared to an active control condition in sixth-grade children," Journal of School Psychology, vol. 52, pp. 263-278, 2014.

[53] L. Flook, S. L. Smalley, M. J. Kitil et al., "Effects of mindful awareness practices on executive functions in elementary school children," Journal of Applied School Psychology, vol. 26, no. 1, pp. 70-95, 2010.

[54] L. A. Jacobson, A. P. Williford, and R. C. Pianta, "The role of executive function in children's competent adjustment to middle school," Child Neuropsychology, vol. 17, pp. 255-280, 2011.

[55] B. D. Singer and A. S. Bashir, "What are executive functions and self-regulation and what do they have to do with languagelearning disorders?" Language, Speech, and Hearing Services in Schools, vol. 30, no. 3, pp. 265-273, 1999.

[56] S. Chinmoy, Meditation: Man-Perfection in God-Satisfaction, AUM Publications, New York, NY, USA, 1989.

[57] N. Park and C. Peterson, "Moral competence and character strengths among adolescents: The development and validation of the Values in Action Inventory of Strengths for Youth," Journal of Adolescence, vol. 29, no. 6, pp. 891-909, 2006.

[58] J. Kabat-Zinn, "Mindfulness-based interventions in context: past, present, and future," Clinical Psychology: Science and Practice, vol. 10, no. 2, pp. 144-156, 2003.

[59] Maharishi Foundation USA, "How is Transcendental Meditation different?" 2016, http://www.tm.org/tm-is-different.

[60] E. S. Huebner, "Preliminary development and validation of a multidimensional life satisfaction scale for children," Psychological Assessment, vol. 6, no. 2, pp. 149-158, 1994.

[61] E. S. Huebner, J. E. Laughlin, C. Ash, and R. Gilman, "Further validation of the Multidimensional Students' Life Satisfaction Scale," Journal of Psychological Assessment, vol. 16, pp. 118-134, 1998.

[62] J. A. Baker, “Teacher-Student Interaction in Urban At-Risk Classrooms: Differential Behavior, Relationship Quality, and Student Satisfaction with School," The Elementary School Journal, vol. 100, no. 1, pp. 57-70, 1999. 
[63] J. J. Froh, J. Fan, R. A. Emmons, G. Bono, E. S. Huebner, and P. Watkins, "Measuring Gratitude in Youth: Assessing the Psychometric Properties of Adult Gratitude Scales in Children and Adolescents," Psychological Assessment, vol. 23, no. 2, pp. 311-324, 2011.

[64] M. E. McCullough, R. A. Emmons, and J.-A. Tsang, "The grateful disposition: a conceptual and empirical topography," Journal of Personality and Social Psychology, vol. 82, no. 1, pp. 112-127, 2002.

[65] M. E. McCullough, J. Tsang, and R. A. Emmons, "Gratitude in intermediate affective terrain: Links of grateful moods to individual differences and daily emotional experience," Journal of Personality and Social Psychology, vol. 86, pp. 295-309, 2004.

[66] F. Faul, E. Erdfelder, A.-G. Lang, and A. Buchner, "G*Power 3: a flexible statistical power analysis program for the social, behavioral, and biomedical sciences," Behavior Research Methods, vol. 39, no. 2, pp. 175-191, 2007.

[67] G. V. Glass, P. D. Peckham, and J. R. Sanders, "Consequences of failure to meet assumptions underlying fixed effects analyses of variance and covariance," Review of Educational Research, vol. 42, no. 3, pp. 237-288, 1972.

[68] J. H. Zar, Biostatistical Analysis, Pearson, Upper Saddle River, NJ, USA, 5th edition, 2010.

[69] A. Seldon and I. Morris, "Should schools be teaching happiness?” Education Review, vol. 20, no. 1, pp. 44-49, 2007. 


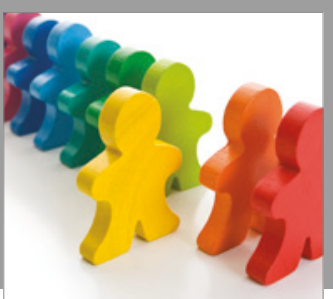

Autism

Research and Treatment
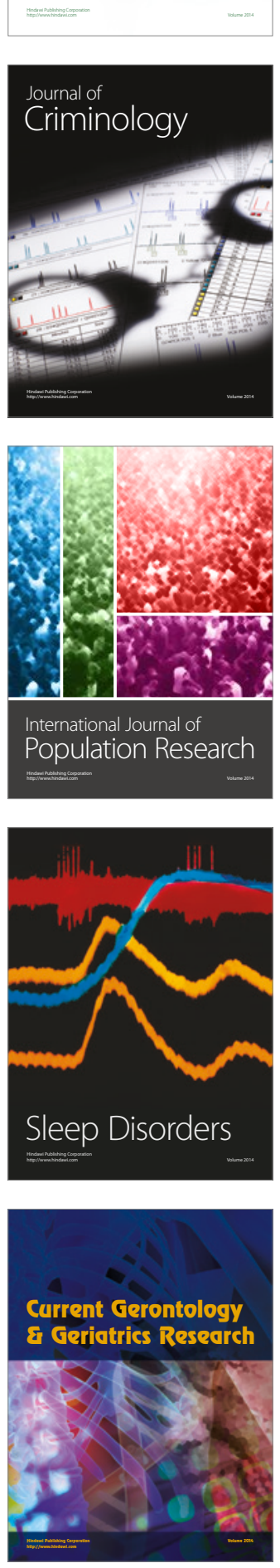

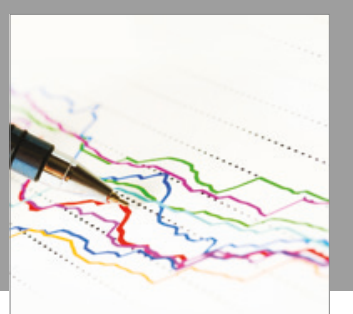

Economics

Research International

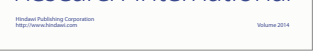

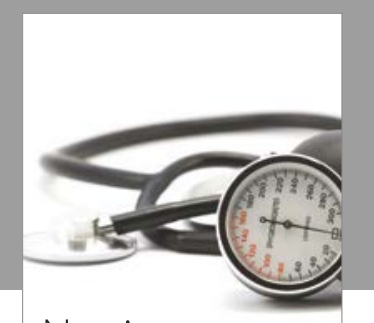

Nursing

Research and Practice

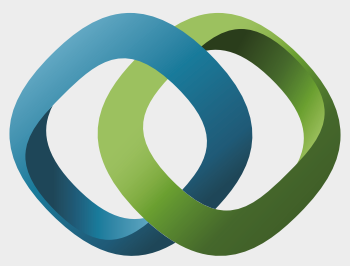

\section{Hindawi}

Submit your manuscripts at

https://www.hindawi.com
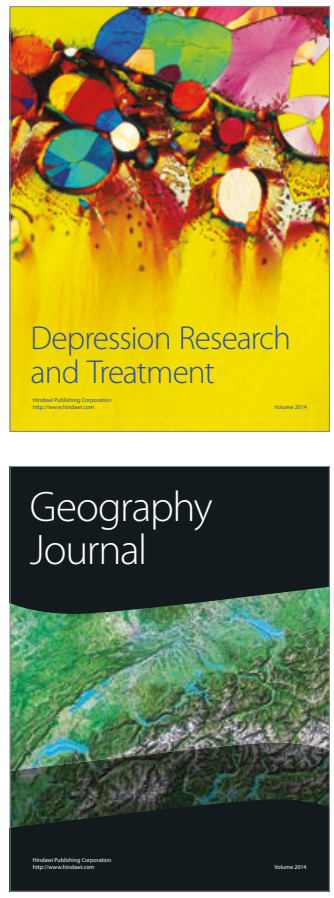
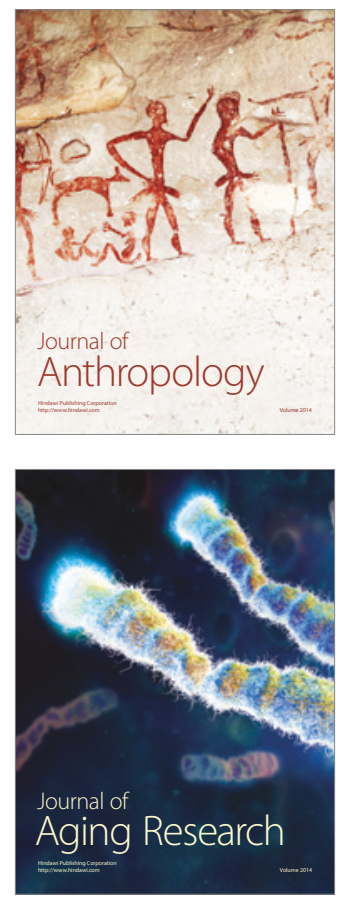
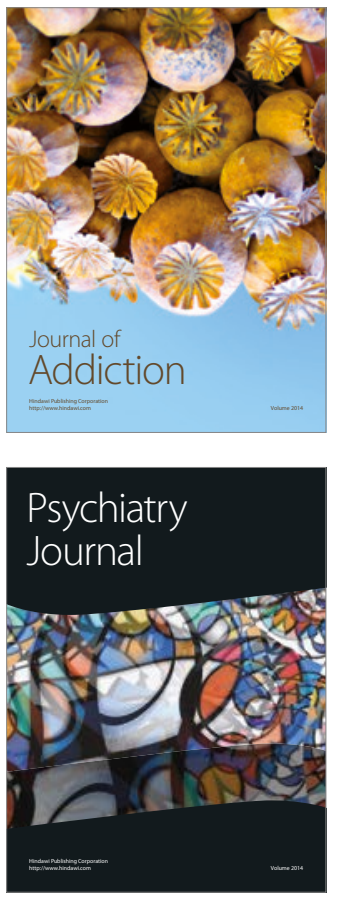

Child Development

Research

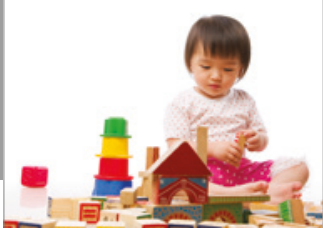

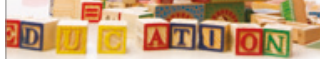
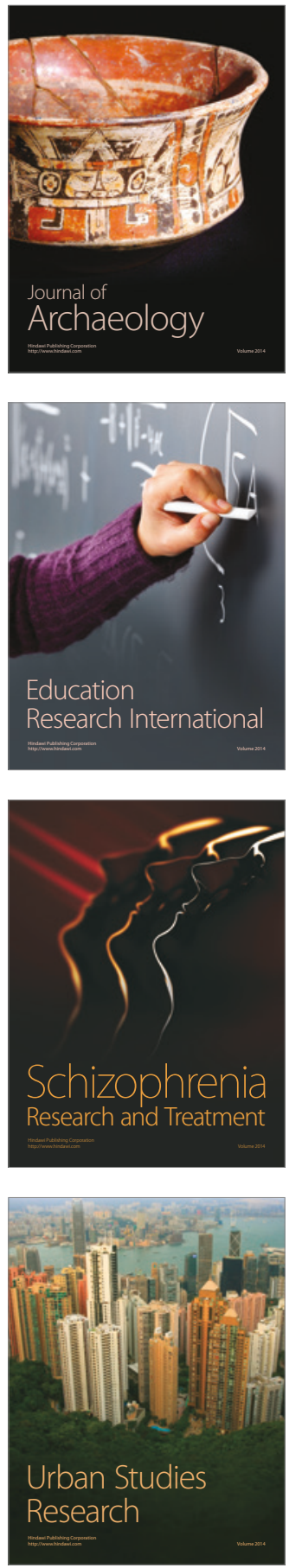